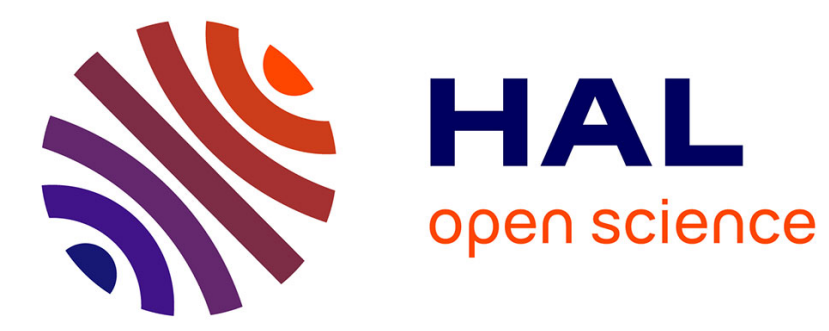

\title{
A new alkaloid from Portulaca oleracea L. and its antiacetylcholinesterase activity
}

Fen Xiu, Xuetao Li, Wenjie Zhang, Fan He, Xixiang Ying, Didier Stien

\section{To cite this version:}

Fen Xiu, Xuetao Li, Wenjie Zhang, Fan He, Xixiang Ying, et al.. A new alkaloid from Portulaca oleracea L. and its antiacetylcholinesterase activity. Natural Product Research, 2018, 33 (18), pp.25832590. 10.1080/14786419.2018.1460833 . hal-02332174

\section{HAL Id: hal-02332174 \\ https://hal.science/hal-02332174}

Submitted on 24 Oct 2019

HAL is a multi-disciplinary open access archive for the deposit and dissemination of scientific research documents, whether they are published or not. The documents may come from teaching and research institutions in France or abroad, or from public or private research centers.
L'archive ouverte pluridisciplinaire HAL, est destinée au dépôt et à la diffusion de documents scientifiques de niveau recherche, publiés ou non, émanant des établissements d'enseignement et de recherche français ou étrangers, des laboratoires publics ou privés. 
A new alkaloid from Portulaca oleracea $L$. and its antiacetylcholinesterase activity

Fen Xiu ${ }^{a}$, Xuetao $\mathrm{Li}^{\mathrm{a}}$, Wenjie Zhang ${ }^{\mathrm{a}}$, Fan $\mathrm{He}^{\mathrm{a}}$, Xixiang Ying ${ }^{\mathrm{a}}$ and Didier Stien ${ }^{\mathrm{b}}$

${ }^{a}$ School of Pharmacy, Liaoning University of Traditional Chinese Medicine, Dalian, People's Republic of China

${ }^{\text {b}}$ Sorbonne Universités, UPMC Univ Paris 06, CNRS, Laboratoire de Biodiversité et Biotechnologies Microbiennes (LBBM), Observatoire Océanologique, Banyuls-sur-Mer, France 


\section{ABSTRACT}

A new alkaloid, $(10 E, 12 E)$-9-ureidooctadeca-10, 12-dienoic acid, named

oleraurea (1) and 10 known compounds, p-hydroxybenzaldehyde (2),

p-hydroxybenzoic acid (3), p-hydroxyacetophenone (4), benzamide (5),

(E)-p-coumaramide (6), (E)-ferulamide (7), soyalkaloid A (8), 8 -

carboline-3-carboxylic acid (9), 2, 3, 4, 9-tetrahydro-1H-pyrido [3, 4-b]

indole-3-carboxylic acid (10), (1S, 3S)-1-methyl-1, 2, 3, 4-tetrahydro-

B-carboline-3-carboxylic acid (11) were obtained from Portulaca oleracea L., in which, compounds 4, 5, 8-11 were isolated from the plant for the first time. The structure of the compound $\mathbf{1}$ was identified using spectroscopic methods including 1D and 2D NMR, HR-ESI-TOFMS. The compounds 1, 5-11 presented anticholinesterase activities, but the $P$. oleracea extract (POE) presented very low anticholinesterase activity.

\section{KEYWORDS}

Portulaca oleracea L.; alkaloid; NMR; anticholinesterase activity 


\section{Introduction}

Portulaca oleracea $\mathrm{L}$. is succulent annual herb belonging to the family

Portulacaceae, order Caryophyllales in phytochemical taxonomy (Lei et al.

2015), which is widely distributed in the tropical and subtropical areas in the world (Zhou et al. 2015). P. oleracea is named 'Ma Chi Xian' because its leaves seem like teeth of horse and taste likes amaranth, also, named 'Chang Shou Cai' because of its cold resistance, tenacious vitality and prolonging lifespan.

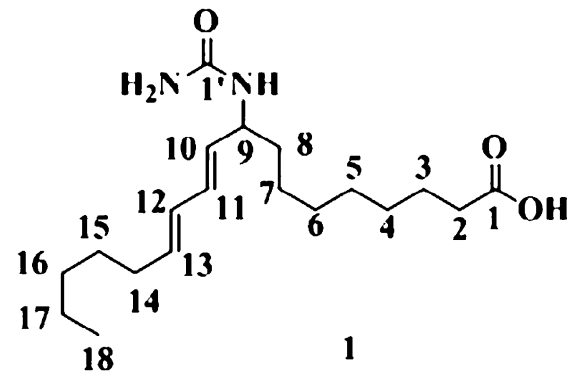

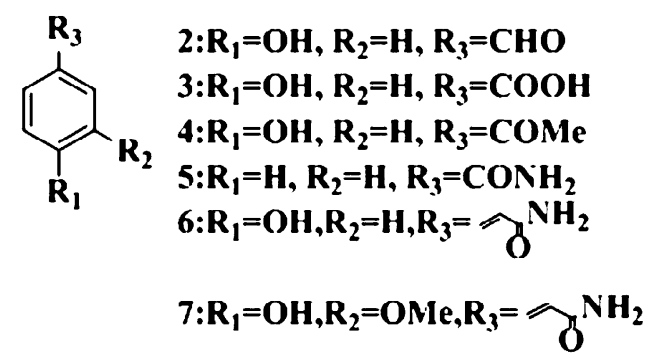<smiles>O=C1OC2CCN=C2c2[nH]c3ccccc3c21</smiles>

8<smiles>O=C(O)c1cc2c(cn1)[nH]c1ccccc12</smiles>

9<smiles>[R]C1NC2Cc3c([nH]c4ccccc34)C(C(=O)O)C2N1</smiles>

10:R=H

$11: R=M e$

Figure 1. Chemical structures of compounds isolated from $P$. oleracea

P. oleracea is regarded as the plant of 'homology of food and medicine' (Liang et al. 2014) because of its safety for daily consumption as a vegetable (Yen et al. 2001) and its many health effects, i.e. anti-inflammatory (Li et al. 2016), antioxidant (Yang et al. 2009), antimicrobia (Nayaka et al. 2014), antidiabetics 
(Li et al. 2009), anti-tumor (Zhao et al. 2013), and the effects should mainly attribute to the constituents in P. oleracea, such as alkaloids (Li et al. 2016; Xu et al. 2016; Li et al. 2017; Zhao et al. 2017), flavonoids (Xu et al. 2006), terpenoids (Xin et al. 2010), organic acids (Wang et al. 2017), phenolic compounds (Erkan 2012), cerebrosides (Zheng et al. 2014).

Concerning alkaloids have a wide range of structural diversity and biological activities, for examples, some alkaloids are anticholinesterase (AChE) inhibitors, which are the useful pathway for curing the Alzheimer's disease (AD) (Richard et al. 2010), in this paper we investigated the alkaloids in $P$. oleracea extract (POE) and evaluated their AChE inhibitory activities. A new alkaloid, (10E, 12E)-9-ureidooctadeca-10, 12-dienoic acid, named oleraurea, together with 10 known compounds were finally obtained (Figure 1). In addition, the anticholinesterase activities of the 11 compounds and the POE were studied by Ellman's colorimetric method with some modifications. The compounds $\mathbf{1 , \mathbf { 8 } - \mathbf { 1 1 }}$ presented higher anticholinesterase activities among the pure compounds with $\mathrm{IC}_{50}$ between $62.22-67.65 \mu \mathrm{M}$, conversely, the POE with $\mathrm{IC}_{50}$ of $257.09 \pm 5.90$ $\mu \mathrm{M}$ nearly presented no anticholinesterase activity, and eserine with $\mathrm{IC}_{50}$ of $29.74 \pm 0.14 \mu \mathrm{M}$ was to be the positive control in the study.

\section{Results and discussion}

\subsection{Structure elucidation}

Compound 1 was a white power, which presented a dark spot at UV $254 \mathrm{~nm}$ and 
a blue fluoresce at UV $365 \mathrm{~nm}$. The UV (MeOH) $\lambda$ max: $226 \mathrm{~nm}$ (Figure S4) and IR: $3442,1650,1606 \mathrm{~cm}^{-1}$ (Figure S5). Its molecular formula was $\mathrm{C}_{19} \mathrm{H}_{34} \mathrm{~N}_{2} \mathrm{O}_{3}$ with 4 degrees of unsaturation which was deduced from the ${ }^{1} \mathrm{H} N M R,{ }^{13} \mathrm{CNMR}$ spectrum data (Table S1) and the HR-ESITOF-MS ion peaks at m/z 339.2650 [M + $\mathrm{H}^{+}$(calc for: 339.2643), $\mathrm{m} / \mathrm{z} 699.5030(2 \mathrm{M}+\mathrm{Na})^{+}$(calc for: 699.5032), $\mathrm{m} / \mathrm{z}$ 337.2512 [M-H] ${ }^{-}$(calc for: 337.2496). The HR-ESI-TOF-MS showed a strong ion peak at $\mathrm{m} / \mathrm{z} 279.2518\left(\mathrm{M}^{+}-\mathrm{HNCONH}_{2}+\mathrm{H}\right)^{+}$(Figure S3.1), belonging to octadecadienoic acid (Huang et al. 2004). Therefore, $\delta_{C} 175.3$ in ${ }^{13}$ C NMR spectrum of compound 1 was assigned to carboxyl group. The ${ }^{1}$ H NMR spectrum (Figure S6) proved the presence of the methyl that gave rise to signals at $\delta_{\mathrm{H}} 0.84(\mathrm{t}, 3 \mathrm{H}, \mathrm{J}=$ $6.7 \mathrm{~Hz})$; the methylenes that gave rise to signals at $\delta_{\mathrm{H}} 1.22(\mathrm{~m}, 10 \mathrm{H}$, overlapped), $1.26(\mathrm{~m}, 2 \mathrm{H}), 1.33(\mathrm{~m}, 2 \mathrm{H}), 1.36(\mathrm{~m}, 2 \mathrm{H}), 1.46(\mathrm{~m}, 2 \mathrm{H}), 2.01(\mathrm{q}, 2 \mathrm{H}, \mathrm{J}=14.4 \mathrm{~Hz})$ and $2.14(\mathrm{~m}, 2 \mathrm{H})$; the methine group that gave rise to signals at $\delta_{H} 4.02(\mathrm{~m}, 1 \mathrm{H})$; the ' - $\mathrm{HNCONH}_{2}$ ' that gave rise to signals at $\delta_{\mathrm{H}} 5.32(2 \mathrm{H}, \mathrm{br})$ and $5.90(\mathrm{~d}, 1 \mathrm{H}, J=$ $8.5 \mathrm{~Hz})$; the olefinic methines that gave rise to signals at $\delta_{H} 5.47(\mathrm{~m}, 1 \mathrm{H}), 5.60$ (m, $1 \mathrm{H})$ and $5.99\left(\mathrm{~d}, 2 \mathrm{H}, J=14.1 \mathrm{~Hz}\right.$, overlapped). The ${ }^{13} \mathrm{C}$ NMR spectrum (Table S1) (Figure S7) and DEPT spectrum (Figure S8) revealed 19 carbon resonances, which include one methyl $\left(\delta_{C} 13.9\right)$, eleven methylenes $\left(\delta_{C} 21.9,24.6,25.3\right.$, $28.4,28.6,28.7,28.8,30.8,31.9,34.1,35.2)$, one methine group $\left(\delta_{C} 50.2\right)$, four 
olefinic methines $\left(\delta_{C} 128.6,129.9,133.3,134.0\right)$ and two quaternary carbons $\left(\delta_{C}\right.$ 158.2, 175.3). The ${ }^{1} \mathrm{H}-{ }^{1} \mathrm{H}$ COSY (Figure S2, S9) showed the strong correlations of H-2/H-3/H-4/H-5/H-6/H7/H-8/H-9/H-10/H-11/H-12/H-13/H-14/H-15/H-16/H-17 /H-18, at the same time, the HMBC correlation (Figure S1, S10) showed correlations from $\mathrm{H}-2$ to $\mathrm{C}-1,3 ; \mathrm{H}-8$ to $\mathrm{C}-7 ; \mathrm{H}-9$ to $\mathrm{C}-10,11 ; \mathrm{H}-10$ to $\mathrm{C}-12 ; \mathrm{H}-13$ to C-11; H-14 to C-12, 13, 15, 16; H-15 to C-13, 14, 16, 17; H-16 to C-17; H-17 to C-16, 18; H-18 to C-16, 17. Therefore, both ${ }^{1} \mathrm{H}-{ }^{1} \mathrm{H}$ COSY and HMBC confirmed the existence of long carbon chain. There is an obvious correlation signal of $\delta_{\mathrm{H}} 2.14$ to $\delta_{C} 175.3$ in the $\mathrm{HMBC}$ spectrum, indicating that a signal at $\delta_{\mathrm{C}} 175.3$ existed in the carbon spectrum. In addition, the downfield chemical shift of methylene protons happened because of $\delta_{\mathrm{H}} 2.14$ connecting with the carboxyl carbon of $\delta_{\mathrm{C}}$ 175.3, and this allowed us to assign $\delta_{\mathrm{H}} 2.14 / \delta_{\mathrm{C}} 34.1$ at $\mathrm{C}-2$. The ${ }^{1} \mathrm{H}-{ }^{1} \mathrm{H}$ COSY correlation suggested the presence of ' $-\mathrm{HNCONH}_{2}$ ' because of the downfield chemical shifts of $\mathrm{H}-9$ and the correlation from $\mathrm{H}-9$ to $\mathrm{NH}$, and the NOESY correlation (Figure S2, S12) from $\mathrm{NH}$ to $\mathrm{NH}_{2}, \mathrm{H}-8,9,10 ; \mathrm{NH}_{2}$ to $\mathrm{NH}, \mathrm{H}-9$ also. NOESY spectrum showed that the four olefinic carbons belong to two double bonds and were respectively assigned to $C-10,11,12$ and 13, the intensive signals leading the adjacent methylene protons shifting to downfield at 31.9 (position 14) and methine protons at 50.2 (position 9), furthermore, the coupling constant $(14.4 \mathrm{~Hz})$ confirmed the trans-configuration of two double 
bonds. Thus, the structure of compound 1 was elucidated as (10E,

12E)-9-ureidooctadeca-10, 12-dienoic acid, named oleraurea.

By comparison of the ${ }^{1} \mathrm{H}$ and ${ }^{13} \mathrm{C}$ NMR spectral data with literature, the 10 known compounds (2-11) were identified, respectively, as

p-hydroxybenzaldehyde (2) (Kim et al. 2003), p-hydroxybenzoic acid (3) (Wang et al. 2000), p-hydroxyacetophenone (4) (Liu et al. 2013), benzamide (5) (Cheng et al. 2017), (E)-p-coumaramide (6) (Kokubun et al. 2012), (E)-ferulamide (7) (Kokubun et al. 2012), soyalkaloid A (8) (Wang et al. 2016), 8-carboline-3-carboxylic acid (9) (Tran et al. 2015), 2, 3, 4, 9-tetrahydro-1H-pyrido [3,4-b]indole-3-carboxylic acid (10) (Goda et al. 1999),

(1S,3S)-1-methyl-1,2,3,4-tetrahydro-6-carboline-3-carboxylic acid (11) (Brossi et al. 1973).

\subsection{Anticholinesterase activity}

$A D$ is the most common form of neurodegenerative disease in the aged and the patient have loss of memory, cognitive abilities and obstacle in behavior (Mohamed et al. 2011). Currently, the more accepted AD pathology is the cholinergic hypothesis and the effective treatment strategy is to inhibit the activity of AChE and improve the level of acetylcholine in the brain (Kurt et al. 2015). Our experiment herein was devoted to search for the effective cholinesterase inhibitors. The anticholinesterase activities of the 11 compounds and the POE were determined using a microplate assay, and $\mathrm{IC}_{50}$ values of the 
11 compounds and the POE were presented in Table S2. The compounds 1, 5-11 isolated from $P$. oleracea ranged 1-35 $\mu \mathrm{M}$ exhibited different degree of activities against the AChE with $\mathrm{IC}_{50}$ values of $62.22 \pm 1.02-121.77 \pm 0.72 \mu \mathrm{M}$ far less than that of POE with $\mathrm{IC}_{50}$ of $257.09 \pm 5.90 \mu \mathrm{M}$, meaning that the POE presented very low anticholinesterase activity which was similar with the results of the literature (Boga, et al. 2011). $I C_{50}$ value of positive control eserine was $29.74 \pm 0.14 \mu \mathrm{M}$.

\section{Experimental}

\subsection{General experimental procedures}

The further separation and purity of compounds 1-11 used a Shimadzu Nexera X2 UHPLC LC-30A system (Shimadzu, Kyoto, Japan) with a UV spectrophotometric detector (SPD-20A), a vacuum degasser (DGU-20A), a solvent delivery pump (LC-30AD) and Lab Station software (Shimadzu). The analytical column was a Diamonsil $C_{18}$ column $(150 \mathrm{~mm} \times 4.6 \mathrm{~mm}$ i.d., $5 \mu \mathrm{m})$ (Dikma Technologies, Bejing, China). The UV spectrum was detected using a HITACHI U-3010 spectrophotometer (Hitachi Ltd, Tokyo, Japan). The IR spectrum was recorded on an IR 200 spectrophotometer (Thermo Electron Corporation, Waltham, MA). The optical rotation was detected on an autopol I antomatic polarmeter (Rudolph Research Analytical, Hackettstown, NJ). The ${ }^{1} \mathrm{H}$ (1D, 2D COSY) and ${ }^{13} \mathrm{C}(1 \mathrm{D}, 2 \mathrm{D}$ HMBC) NMR spectra were determined using an 
AVANCE $500 \mathrm{MHz}$ instrument (Bruker Corporation, Switzerland) in MeOD and DMSO, using TMS as an internal standard. An Agilent 1290 UHPLC system coupled to an Agilent 6520 quadrupole-time of flight mass spectrometer (Agilent, Waldbronn, Germany) was carried out to reference UHPLC-Q-TOF/MS spectra. The acetylcholinesterase inhibitory assay was performed in 96-well microplates and determinedusing an Emax precision microplate reader (Nanjing defe experiment equipment co. LTD).

\subsection{Plant materials and reagents}

The air-dried aerial parts P. oleracea was collected from Shijiazhuang, Hebei, China in June 2014. The plant material was kindly identified by Professor Dr. Xixiang Ying. Voucher specimens (No. 20140312) were deposited at School of Pharmacy, Liaoning University of Traditional Chinese Medicine. Methanol and acetonitrile were all of HPLC grade purchased from Damao Chemical Reagent Plant (Tianjin, China). All other reagents were analytical grade provided by Jinfeng Chemical Factory (Tianjin, China) and the water was WAHAHA purified water (Shenyang, China). Sodium dihydrogen phosphate and disodium hydrogen phosphate were purchased from Sinopharm Chemical Reagent Co., Ltd. Eserine was provided by Biochempartner. 5, 5-dithiobis-2-nitrobenzoic acid (DTNB) was purchased from Shanghai Jinsui Bio-Technology Co., Ltd. Acetylthiocholine iodide (ATCI) and AChE were provided by Dalian Meilun Biotech Co., Ltd. Polyamide and silica gel (Qingdao Marine Chemical Co., 
Qingdao, China). Sephadex LH-20 and ODS (GE Healthcare, Marlborough, MA) were used for column chromatography (CC). TLC was performed on TLC plates pre-coated with silica gel GF254 (Qingdao Marine Chemical Co., Qingdao, China).

\subsection{Extraction and isolation}

A sample $(150 \mathrm{~kg})$ of the air-dried aerial parts $P$. oleracea was extracted with $50 \%$ ethanol twice under reflux for $2 \mathrm{~h}$ each time. The ethanol POE was concentrated under reduced pressure to yield a crude POE $(21 \mathrm{~kg})$ and then subjected to chromatography on a silica-gel (80-100 mesh) column eluted sequentially with ethyl acetate and ethanol $(1: 0,4: 1,2: 1, v / v)$. The part of 2:1 was provided ( $1 \mathrm{~kg}$ ) after concentrated, then the POE was divided into two equal parts, adsorbed on a polyamide resin (80-100 mesh, Taizhou Luqiao Sijia Biochemical Plastic Factory, Zhejiang, China) column eluted with equal distilled water, 30, 50 and $70 \%$ ethanol, respectively. The fractions of $30 \%$ ethanol (150 g) were evaporated and applied to a silica-gel (200-300 mesh, approximately $2.5 \mathrm{~kg})$ column $(8 \times 120 \mathrm{~cm})$, eluting sequentially withi isocratic ethyl acetate and methanol $(5: 1,2: 1,1: 2,1: 3, v / v)$ for further purification to obtain eluates 1-4. The resulting Fr. 1 (ethyl acetate and methanol 5:1, $14 \mathrm{~g}$ ) was applied to 20-40 $\mu \mathrm{m}$ ODS- $C_{18}(150 \mathrm{~g})$ column $(\phi 3 \times 70 \mathrm{~cm})$ under medium pressure and eluted with $\mathrm{MeOH}-\mathrm{H}_{2} \mathrm{O}(20: 80,40: 60,60: 40,80: 20,100: 0, \mathrm{v} / \mathrm{v})$ to obtain 5 fractions (200 mL each). The fourth was applied to Sephadex LH-20 (150 g) 
column $(\varphi 2 \times 150 \mathrm{~cm})$ using methanol as eluant to obtain a pure mixture. Final separation was performed on a UHPLC equipped with an autosampler and eluted with the mobile phase consisted of acetonitrile-0.1\% formic acid water (49:51, v/v), yielding compound 1 (5 mg, purity > 98\% with UHPLC, $\left.t_{R} 13.45 \mathrm{~min}\right)$. The eluate 3 was purified with Sephadex LH-20 $(150 \mathrm{~g})$ column $(\varphi 2 \times 150 \mathrm{~cm})$ and eluted with $\mathrm{MeOH}$, followed by UHPLC preparation using a mobile phase of $\mathrm{MeOH}-\mathrm{H}_{2} \mathrm{O}$ (15:85), yielding six known compounds, $p$-hydroxybenzaldehyde (2) (18 mg, purity $>98 \%$ with UHPLC, $t_{R} 18.34 \mathrm{~min}$ ), $p$-hydroxybenzoic acid (3) (8 mg, purity $>98 \%$ with UHPLC, $\left.t_{R} 8.17 \mathrm{~min}\right), p$-hydroxyacetophenone (4) $(5 \mathrm{mg}$, purity $>98 \%$ with UHPLC, $t_{R} 17.59 \mathrm{~min}$ ), benzamide $(5)$ (10 mg, purity $>98 \%$ with UHPLC, $t_{R} 11.61 \mathrm{~min}$ ), (E)-p-coumaramide (6) (7 mg, purity $>98 \%$ with UHPLC, $t_{R} 8.04 \mathrm{~min}$ ) and (E)-ferulamide (7) (4 mg, purity > 98\% with UHPLC, $t_{R}$ $7.38 \mathrm{~min})$. The eluate 1 was separated by UHPLC and eluted with the mobile phase consisted of acetonitrile $-0.1 \%$ formic acid water $(20: 80, \mathrm{v} / \mathrm{v})$, yielding five known compounds, soyalkaloid A (8) (15 mg, purity > 98\% with UHPLC, $t_{R} 18.12$ min), 6-carboline-3-carboxylic acid (9) (6 mg, purity > 98\% with UHPLC, $t_{R} 7.32$ min), 2,3,4,9-tetrahydro-1H-pyrido[3, 4-b]indole-3-carboxylic acid (10) (10 mg, purity $>98 \%$ with UHPLC, $\left.t_{R} 5.09 \mathrm{~min}\right)$, (1S,3S)-1-methyl-1,2,3,4-tetrahydro-6-carboline-3-carboxylic acid (11) (15 mg, purity $>98 \%$ with UHPLC, $\left.t_{R} 6.87 \mathrm{~min}\right)$. The flow rate was $1.0 \mathrm{~mL} / \mathrm{min}$ and the 
column temperature was $40^{\circ} \mathrm{C}$.

oleraurea (1): white power; [ $\alpha] 20 \mathrm{D}+9.8\left(\mathrm{c} \mathrm{0.22,} \mathrm{CHCl}_{3}\right)$; UV (MeOH) $\lambda \max 226$ $\mathrm{nm}$; IR (KBr) $\mathrm{v}_{\mathrm{N}-\mathrm{H}} 3442 \mathrm{~cm}^{-1}, \mathrm{v}_{\mathrm{CH}} 2932,2861 \mathrm{~cm}^{-1}, \mathrm{v}_{\mathrm{C}=\mathrm{O}} 1650,1606 \mathrm{~cm}^{-1}, \mathrm{v}_{\mathrm{CH}} 1355$ $\mathrm{cm}^{-1} ;{ }^{1} \mathrm{H}$ and ${ }^{13} \mathrm{C}$ NMR spectroscopic data (DMSO), see Table S1;

UHPLC-Q-TOF/MS m/z 339.2650 [M + H] ${ }^{+}$(calcd: 339.2643 ), m/z 699.5030 (2 M

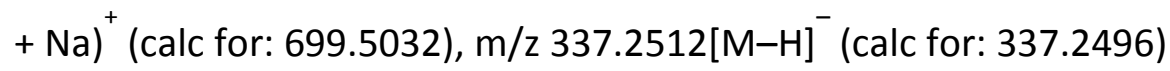

\subsection{Acetylcholinesterase activity assay}

Acetylcholinesterase activity was tested by Ellman's colorimetric method (Ellman et al. 1961) with some modifications. In the 96-well plates, $140 \mu \mathrm{L}$ PBS (0.1 M, pH = 8.0, containing $0.1 \mathrm{~mol} / \mathrm{L} \mathrm{NaH}_{2} \mathrm{PO}_{4}$ and $\mathrm{Na}_{2} \mathrm{HPO}_{4}$ ), $10 \mu \mathrm{L}$ DTNB (15 $\mathrm{mmol} / \mathrm{L}), 15 \mu \mathrm{LAChE}(0.2 \mathrm{U} / \mathrm{mL})$ and $20 \mu \mathrm{L}$ of a serially diluted solution of the tested samples were mixed and incubated for $10 \mathrm{~min}$, then added with $10 \mu \mathrm{L}$ ATCl $(15 \mathrm{mmol} / \mathrm{L})$ and incubated at $20^{\circ} \mathrm{C}$ for $10 \mathrm{~min}$. The absorbance of each well was determined at $405 \mathrm{~nm}$ using a microplate reader. In the blank group, the tested sample was replaced by methanol. The percentage inhibition was calculated according to the following formula: inhibition activity $(\%)=[($ blank group - test group)/blank group] $\times 100 \%$. Anticholinesterase activities were evaluated by the value of $\mathrm{IC}_{50}$.

\section{Conclusion}


In the study, a new alkaloid, (10E, 12E)-9-ureidooctadeca-10, 12-dienoic acid, along with 10 known compounds were isolated from $P$. oleracea, in which, compounds $4, \mathbf{5}, \mathbf{8}, \mathbf{9}, \mathbf{1 0}, \mathbf{1 1}$ were isolated from the plant for the first time, and compounds $1,5,6,7,8,9,10,11$ exhibited higher anticholinesterase activities than that of the POE, suggested that the natural compounds in the $P$. oleracea presented a better pharmacological activities than that the extract, and therefore it is interesting to isolate more natural bioactive compounds from $P$. oleracea in the further study.

\section{Disclosure statement}

No potential conflict of interest was reported by the authors.

\section{Funding}

This work was supported by the National Natural Science Foundation of China [grant number 81573546$]$.

\section{References}

Boğa M, Hacıbekiroğlu I, Kolak U. 2011. Antioxidant and anticholinesterase activities of eleven edible plants. Pharm Biol. 49:290-295.

Brossi A, Focella A, Teitel S. 1973. Alkaloids in mammalian tissues. 3.

Condensations of L-tryptophan and L-5-hydroxytryptophan with formaldehyde and acetaldehyde. J Med Chem. 16:418-420. 
Cheng J, Li MG, Ding ZG, Wen ML, Zhao JY. 2017. Secondary metabolites of Tin Tailings Streptomyces AE21985. Nat Prod Res Dev. 29:190-197.

Ellman GL, Courtney KD, Andres V Jr, Featherstone RM. 1961. A new and rapid colorimetric determination of acetylcholinesterase activity. Biochem Pharmacol. 7:88-95.

Erkan N. 2012. Antioxidant activity and phenolic compounds of fractions from Portulaca oleracea L. Food Chem. 133:775-781.

Goda Y, Hoshino K, Akiyama H, Ishikawa T, Abe Y, Nakamura T, Otsuka H, Takeda Y, Tanimura A, Toyoda M. 1999. Constituents in watercress: inhibitors of histamine release from RBL-2H3 cells induced by antigen stimulation. Biol Pharm Bull. 22:1319-1326.

Huang XS, Gao S, Fan LH, Yu SS, Liang XT. 2004. Research on the chemical constituents of Tylophora atrofolliculata Metc. China J Chin Mater Med. 29:1108-1109.

Kim H, Ralph J, Lu F, Ralph SA, Boudet AM, MacKay JJ, Sederoff RR, Ito T, Kawai 
S, Ohashi H. 2003. NMR analysis of lignins in CAD-deficient plants. Part 1. Incorporation of hydroxycinnamaldehydes and hydroxybenzaldehydes into lignins. Org Biomol Chem. 1:268-281.

Kokubun T, Kite GC, Veitch NC, Simmonds MS. 2012. Amides and an alkaloid from Portulaca oleracea. Nat Prod Commun. 7:1047-1050.

Kurt BZ, Gazioglu I, Sonmez F, Kucukislamoglu M. 2015. Synthesis, antioxidant and anticholinesterase activities of novel coumarylthiazole derivatives. Bioorg Chem. 59:80-90.

Lei X, Li JM, Liu B, Zhang N, Liu HY. 2015. Separation and identification of four new compounds with antibacterial activity from Portulaca oleracea $\mathrm{L}$. Molecules. 20:16375-16387.

Li FL, Li QW, Gao DW, Yong P, Feng CN. 2009. Preparation and antidiabetic activity of polysaccharide from Portulaca oleracea L. Afr J Biotechnol. 8:569-573.

Li CY, Meng YH, Ying ZM, Xu N, Hao D, Gao MZ, Zhang WJ, Xu L, Gao YC, Ying XX. 2016. Three novel alkaloids from Portulaca oleracea L. and their anti-inflammatory effects. J Agric Food Chem. 64:5837- 5844.

Li CY, Ying ZM, Gao MZ, Wei WJ, Hao D, Xu L, Tao XJ, Zhang WJ, Ying XX, Jing L. 
2017. Two new similar alkaloids from Portulaca oleracea L. Nat Prod Res. 31:1792-1798.

Liang X, Tian JL, Li L, Gao J, Zhang QY, Gao PY, Song SJ. 2014. Rapid determination of eight bioactive alkaloids in Portulaca oleracea L. by the optimal microwave extraction combined with positivenegative conversion multiple reaction monitor (+/-MRM) technology. Talanta. 120:167-172.

Liu X, Wang B, Gao Y, Li RT, Li HZ. 2013. Phenolic constituents from Chinese dragon's blood and its ultraviolet spectrum characteristic. Nat Prod Res Dev. 25:1060-1066.

Mohamed T, Zhao X, Habib LK, Yang J, Rao PP. 2011. Design, synthesis and structure-activity relationship (SAR) studies of 2,4-disubstituted pyrimidine derivatives: dual activity as cholinesterase and $A \beta a g g r e g a t i o n$ inhibitors. Biorg Med Chem. 19:2269-2281.

Nayaka HB, Londonkar RL, Umesh MK, Tukappa A. 2014. Antibacterial attributes of apigenin, isolated from Portulaca oleracea L. Int J Bacteriol. 2014:175851. Richard MR, In KR, Robert V. 2010. Isolation of acetylcholinesterase inhibitory alkaloids from Nerine bowdenii. Nat Prod Res. 24:222-225.

Tran TD, Pham NB, Ekins M, Hooper JNA, Quinn RJ. 2015. Isolation and total synthesis of stolonines $\mathrm{A}-\mathrm{C}$, unique taurine amides from the Australian marine 
tunicate Cnemidocarpa stolonifera. Mar Drugs. 13:4556-4575.

Wang M, Kikuzaki H, Zhu N, Sang S, Nakatani N, Ho CT. 2000. Isolation and structural elucidation of two new glycosides from sage (Salvia officinalis L.). J Agric Food Chem. 48:235-238.

Wang T, Zhao J, Li X, Xu QM, Liu Y, Khan IA, Yang S. 2016. New alkaloids from green vegetable soybeans and their inhibitory activities on the proliferation of concanavalin a-activated lymphocytes. J Agric Food Chem. 64:1649-1656.

Wang HQ, Zhang LY, Wang YY. 2017. Isolating and identifying organic acids from Portulaca oleracea and determining their anti-cyanobacterial activity. Pol J Environ Stud. 26:441-445.

Xin HL, Xu YF, Hou YH, Zhang YN, Yue XQ, Lu JC, Ling CQ. 2010. Two novel triterpenoids from Portulaca oleracea L. Helv Chim Acta. 91:2075-2080.

Xu L, Ying ZM, Wei WJ, Hao D, Wang HB, Zhang WJ, Li CY, Jiang MY, Ying XX, Liu J. 2016. A novel alkaloid from Portulaca oleracea L. Nat Prod Res. 31:902-908.

Xu X, Yu L, Chen G. 2006. Determination of flavonoids in Portulaca oleracea L. by capillary electrophoresis with electrochemical detection. J Pharm Biomed Anal. 41:493-499.

Yang Z, Liu C, Lan X, Zheng Y. 2009. Phenolic alkaloids as a new class of 
antioxidants in Portulaca oleracea. Phytother Res. 23:1032-1035.

Yen GC, Chen HY, Peng HH. 2001. Evaluation of the cytotoxicity, mutagenicity and antimutagenicity of emerging edible plants. Food Chem Toxicol. 39:1045-1053.

Zhao R, Gao X, Cai YP, Shao XY, Jia GY, Huang YL, Qin XG, Wang JW, Zheng XL. 2013. Antitumor activity of Portulaca oleracea L. polysaccharides against cervical carcinoma in vitro and in vivo. Carbohydr Polym. 96:376-383.

Zhao CC, Ying ZM, Tao XJ, Jiang MY, Ying XX, Yang GL. 2017. A new lactam alkaloid from Portulaca oleracea L. and its cytotoxity. Nat Prod Res. doi:10.1080/14786419.2017.1385022.

Zheng GY, Qu LP, Yue XQ, Gu W, Zhang H, Xin HL. 2014. Portulacerebroside A induces apoptosis via activation of the mitochondrial death pathway in human liver cancer HCCLM3 cells. Phytochem Lett. 7:77-84.

Zhou YX, Xin HL, Rahman K, Wang SJ, Peng C, Zhang H. 2015. Portulaca oleracea L.: a review of phytochemistry and pharmacological effects. Biomed Res Int 2015: 925631. 